\title{
Nicotinic Acetylcholine Receptor $\alpha 7$ Subunit Is an Essential Regulator of Seizure Susceptibility
}

\author{
Peng Sun ${ }^{1}$, Da-Gang Liu ${ }^{2}$ and Xiang-Ming Ye ${ }^{1 *}$ \\ ${ }^{1}$ Rehabilitation \& Sports Medicine Research Institute of Zhejiang Province, Zhejiang Provincial People's Hospital, People's \\ Hospital of Hangzhou Medical College, Hangzhou, China, ${ }^{2}$ Department of Neurosurgery Medicine, Weihai Central Hospital, \\ Weihai, China
}

A large body of data has confirmed that $\alpha 7$ nicotinic acetylcholine receptors (nAChRs) play a pivotal role in cognition, memory, and other neuropsychiatric diseases, but their effect on seizure susceptibility in C57BL/6 wild-type mice is not fully understood. Here, we showed that decreased activity of $\alpha 7$ nAChRs could increase the excitability of CA1 pyramidal neurons and shorten the onset time of epilepsy in pilocarpine-induced mouse models. However, compared with the control group, there was no apparent effect of increasing the activity of $\alpha 7$ nAChRs. Moreover, the expression of $\alpha 7$ nAChRs is downregulated in human epileptogenic tissues. Taken together, our findings indicate that $\alpha 7 \mathrm{nAChR}$ is an essential regulator of seizure susceptibility.

OPEN ACCESS

Edited by:

Cenglin Xu,

Zhejiang University, China

Reviewed by:

Ying Wang,

Qingdao University, China

Qianfa Long,

Xi'an Central Hospital, China

*Correspondence:

Xiang-Ming Ye

yexm1020@sohu.com

Specialty section:

This article was submitted to

Epilepsy,

a section of the journal

Frontiers in Neurology

Received: 21 January 2021 Accepted: 12 March 2021

Published: 12 April 2021

Citation:

Sun P, Liu D-G and Ye X-M (2021) Nicotinic Acetylcholine Receptor $\alpha 7$ Subunit Is an Essential Regulator of Seizure Susceptibility.

Front. Neurol. 12:656752.

doi: 10.3389/fneur.2021.656752
Keywords: cholinergic receptors, $\alpha 7$ nicotinic acetylcholine receptors, epilepsy, seizure susceptibility, CA1 pyramidal neuron

\section{INTRODUCTION}

Nicotinic acetylcholine receptors (nAChRs) are a family of ligand-gated, pentameric ion channels. Understanding the precise roles of nAChRs remains a challenge because they can modulate cholinergic activities both postsynaptically and presynaptically (1). In humans, there are 16 different subunits $(\alpha 1-7, \alpha 9-10, \beta 1-4, \delta, \varepsilon, \gamma)$ of nAChRs, which can be found both in the peripheral and central nervous systems (2-4). Of these, 12 are associated with a wide spectrum of physiological and pharmacological functions (5). The main function of nAChRs is to regulate neuronal plasticity (6) and neuroprotection $(7,8)$, and the most abundant $\mathrm{nAChR}$ subunits are the $\alpha 4 \beta 2$ and $\alpha 7$ subunits within the central nervous system. Mutations in the transmembrane regions of the neuronal $\alpha 4 \beta 2$ subunit receptors in the neocortex and thalamus can cause autosomal dominant nocturnal frontal lobe epilepsy (9), which is a focal epilepsy in the frontal lobe with attacks typically arising during non-rapid eye movement sleep (10). The $\alpha 7$ subunit is expressed widely in the brain with its highest levels observed in the hippocampus and cortex (11), and its role has been associated with both impairment in cognition and neuropsychiatric phenotypes (12-15).

Our previous studies have indicated that activation of $\alpha 7 \mathrm{nAChR}$ could decrease seizure susceptibility in Chat-Mecp2 ${ }^{-/ y}$ mice (16), but the role of $\alpha 7 \mathrm{nAChR}$ in seizure susceptibility in C57BL/6 wild-type mice and humans remains uncertain. In the present study, we explored the function of $\alpha 7 \mathrm{nAChRs}$ in seizure susceptibility in wild-type mice. We revealed that decreased $\alpha 7 \mathrm{nAChR}$ activity in CA1 parvalbumin (PV) neurons in the hippocampus could increase seizure susceptibility in wild-type mice, while the increased activity of $\alpha 7 \mathrm{nAChR}$ had no significant effect on seizure susceptibility. We also tested the expression of $\alpha 7 \mathrm{nAChR}$ that was downregulated in tissues of humans, experiencing epilepsy after traumatic brain injury or intracerebral hemorrhage. Our findings suggest that $\alpha 7 \mathrm{nAChR}$ is an essential regulator of seizure susceptibility. 


\section{MATERIALS AND METHODS}

All human material was reviewed and approved by the Medical Ethical Committee of Zhejiang Provincial People's Hospital, People's Hospital of Hangzhou Medical College (No. 2019KY255) based on the Code of Ethics of the World Medical Association. All participants provided written informed consent. All animal experimental procedures were examined and approved by the Animal Advisory Committee of Zhejiang Provincial People's Hospital, the People's Hospital of Hangzhou Medical College based on the National Institutes of Health Guide for the Care and Use of Laboratory Animals.

\section{Animals and Reagents}

We used C57BL/6 wild-type mice to complete the experiment. For acute pilocarpine-induced epilepsy models, C57BL/6 wildtype male mice weighing 25-30g were used. Before the behavioral test, we kept the mice in a $12 / 12 \mathrm{~h}$ light/dark cycle, and the environmental conditions were controlled. Mice with abnormal body weight and appearance were excluded from the behavioral test. Sexually dimorphic observations were not observed. The primary antibodies used were rabbit polyclonal anti- $\alpha 7$ nAChR (Santa Cruz Biotechnology, USA, Cat\#: sc-5544), and rabbit polyclonal anti- glyceraldehyde 3phosphate dehydrogenase (GAPDH) (Cell Signaling Technology, Cat\#:5014S). MLA was purchased from Abcam (UK), while pilocarpine and PNU282987 were purchased from SigmaAldrich (USA).

\section{Immunohistochemistry}

We anesthetized the mice and perfused their brain vessel with $4 \%$ paraformaldehyde dissolved in phosphate-buffered saline (PBS). We cut and fixed the whole brains in paraformaldehyde at $4{ }^{\circ} \mathrm{C}$ overnight and further dehydrated the brains in $30 \%$ sucrose in PBS. According to anatomical landmarks, brain sections were cut $35-\mu \mathrm{m}$-thick from the regions of interest using a freezing microtome. We treated the brain sections with $10 \%$ (v/v) normal donkey serum for immunolabeling in PBS containing $0.3 \%$ Triton X-100. Subsequently, we incubated the brain sections with antibodies against anti- $\alpha 7 \mathrm{nAChR}(1: 100)$ at $4{ }^{\circ} \mathrm{C}$ overnight. We visualized the immunoreactivity with the secondary antibodies of Alexa Fluor 594 donkey anti-mouse, Alexa Fluor 633 donkey anti-goat, and Alexa Fluor 488 donkey anti-rabbit IgG (1:400). We visualized the immunofluorescent images by confocal microscopy (FV1000 Laser scanning confocal microscope, USA).

\section{Human Tissue Preparation and Western Blot Analysis}

We dissected $1 \mathrm{~g}$ of epilepsy tissue from fresh frozen brain sections that were maintained at $-80^{\circ} \mathrm{C}$. The tissue was homogenized in a lysis buffer (Beyotime Biotechnology, China) containing $1 \mathrm{mM}$ protease inhibitor phenylmethylsulfonyl fluoride (PMSF) (Beyotime Biotechnology). We collected the supernatants after centrifugation for $10 \mathrm{~min}$ at $15000 \mathrm{rpm}$. After the protein concentration was measured using Bradford's solution (Beyotime Biotechnology), we boiled the samples in a loading buffer containing equivalent amounts of protein for 5 min (Beyotime Biotechnology). We performed sodium dodecyl sulfate-polyacrylamide gel electrophoresis and transferred proteins to an Immobilon polyvinylidene fluoride (PVDF) membrane (Millipore) for $100 \mathrm{~min}$ at $300 \mathrm{~mA}$. We incubated the membranes with primary antibodies against anti- $\alpha 7 \mathrm{nAChR}$ (1:100) after blocking with Tris-buffered saline buffer with Tween 20 (TBST) solution (50 mM Tris- $\mathrm{HCl}, \mathrm{pH} 7.5,150 \mathrm{mM}$ $\mathrm{NaCl}$, and $0.1 \%$ Tween 20) containing 5\% skimmed milk for $1 \mathrm{~h}$ at room temperature. After washing with TBST, we incubated the blots with secondary antibodies $(1: 7,500)$ for $1 \mathrm{~h}$ at room temperature. We detected the signals with enhanced chemiluminescence and developed them on an X-ray film. We digitized the immunoblots on a flatbed scanner and quantified the images using the US National Institutes of Health Image program for densitometric quantification.

\section{Surgeries and Electroencephalogram Measurements}

We secured the mice in a stereotactic head frame and made an incision along the midline after the mice were anesthetized with isoflurane. We used $8 \% \mathrm{H}_{2} \mathrm{O}_{2}$ to observe the bregma and the posterior. We placed the electrode over the cranium with three screws (three positions: the first screw (left): AP: $+1.5 \mathrm{~mm}$, lateral: $+1.5 \mathrm{~mm}$; the second and the third screws: A-P: $-3 \mathrm{~mm}$, lateral: $\pm 3 \mathrm{~mm})$. We placed the cannula (intraventricular drug administration) into the CA1 in the hippocampus (position (right): A-P: $-1.94 \mathrm{~mm}$, lateral: $\pm 1.1 \mathrm{~mm}$ depth: $-2.0 \mathrm{~mm}$ ). We recorded the electroencephalogram (EEG) results in freely moving mice for 1 week after the surgery. $\alpha 7$ nAChR agonist (PNU282987, a selective $\alpha 7$ nAChR agonist, $1 \mathrm{M}$ ) and antagonist (methyllycaconitine citrate (MLA), a specific $\alpha 7 \mathrm{nAChR}$ blocker, $100 \mathrm{nM}$ ) were injected into the hippocampus in the CA1 by microtubule drug administration. Pilocarpine was injected into the peritoneal cavity following intraperitoneal administration.

We defined the abnormal wave as an amplitude $>400 \mathrm{mV}$. We assessed the pilocarpine-induced seizure stages as follows: onset time was measured from the moment the C57BL/6 mice were injected with pilocarpine until the first epileptic waves were observed. The latency of generalized tonic-clonic (GTC) seizure was measured from the moment the $\mathrm{C} 57 \mathrm{BL} / 6$ mice, were injected with pilocarpine until the first GTC seizure epileptic waves were observed. The latency of death was measured from the moment the mice were injected with injection pilocarpine, until the death of the mice.

\section{Electrophysiology}

Coronal slices of the hippocampus were performed in approximately 4- weeks-old mice. Slices $(300 \mu \mathrm{m})$ were prepared with a Vibroslice (Leica VT 1000S) in ice-cold artificial cerebrospinal fluid (ACSF: $125 \mathrm{mM} \mathrm{NaCl}, 3 \mathrm{mM} \mathrm{KCl}$, $1.25 \mathrm{mM}$ NaH2PO4, $2 \mathrm{mM}$ MgSO4, $2 \mathrm{mM} \mathrm{CaCl} 2,25 \mathrm{mM}$ $\mathrm{NaHCO} 3$ and $10 \mathrm{mM}$ glucose). After recovery for $\sim 60 \mathrm{~min}$, incubation in ACSF at $33^{\circ} \mathrm{C}$ was followed by $\sim 60 \mathrm{~min}$ at $22^{\circ} \mathrm{C}$, when slices were transferred to the recording chamber and superfused $\left(3 \mathrm{~mL} \mathrm{~min}{ }^{-}\right)$with ACSF at $32-33^{\circ} \mathrm{C}$. All solutions 
were saturated with $95 \% \mathrm{O}_{2}$ and $5 \% \mathrm{CO}_{2}$. The neurons were identified in the brain sections using an upright microscope equipped with a $40 \times$ water-immersion lens (Nikon, Eclipse FN1, Japan), and the electrical activity was recorded using whole-cell technology (MultiClamp 700-B Amplifier, Digidata 1440 A analog-to-digital converter, and PCLAMP 10.2 software, Axon Instruments Molecular Devices, USA). Pyramidal neurons were recorded in the hippocampal CA1 region. Glass pipettes (3-4.5 $\mathrm{M} \Omega$ ) used for whole-cell recording were filled with internal recording solution: $110 \mathrm{mM} \mathrm{K}$-gluconate, $40 \mathrm{mM} \mathrm{KCl}$, $10 \mathrm{mM}$ HEPES, $2 \mathrm{mM}$ Mg2ATP, $0.5 \mathrm{mM} \mathrm{NaGTP}$, and $0.2 \mathrm{mM}$ EGTA; pH was adjusted to 7.25 with $10 \mathrm{M} \mathrm{KOH}$. We also added DL-2-amino-5-phosphonovaleric acid (DL-AP5; $50 \mu \mathrm{M}$, Tocris Bioscience), 6, 7-dinitroquinoxaline-2, 3-dione (DNQX; $20 \mu \mathrm{M}$, Tocris Bioscience) and picrotoxin (100 $\mu \mathrm{M}, \mathrm{Abcam})$, to block AMPA-mediated, NMDA-mediated, and GABA-mediated synaptic transmission.

\section{Statistical Analysis}

Unless otherwise stated, we expressed the data as mean \pm standard error of the mean (SEM); error bars show the SEM ( $n$ $=$ number of samples). A two-tailed Student's $t$-test was used to compare the means from the same group of cells. The differences between more than two groups were tested with two-way analysis of variance. Differences were considered significant at $P<0.05$.

\section{RESULTS}

\section{Expression of $\alpha 7 \mathrm{nAChR}$ in the CA1 Neurons in the Hippocampus}

Mice expressing the channelrhodopsin-2 (ChR2) protein under the control of the choline acetyltransferase (ChAT, a marker for cholinergic neurons) promoter (ChAT-ChR2-EYFP) were used in this study. The hippocampus has been reported to be the main target for the projection of basal forebrain cholinergic neurons (17). To confirm this, we stained the NeuN in hippocampal CA1 neurons in ChAT-ChR2-EYFP mice (Figure 1A. left). We found that there are lots of cholinergic neuron fiber projections in this area (Figure 1A. middle).

After merging, the results showed that hippocampus CA1 neurons receive dense cholinergic projections (Figure 1A. right). Previous studies showed that the main target projection neurons of $\alpha 7 \mathrm{nAChRs}$ are the PV-positive interneurons, which are the most prominent GABAergic neurons in the hippocampus (16). Therefore, we stained $\alpha 7 \mathrm{nAChRs}$ in the CA1 neurons (Figure 1B). The results showed that $\alpha 7 \mathrm{nAChRs}$ were concentrated in PV GABAergic neurons, with little expression in non-PV neurons in the CA1 (Figure 1B). Taken together, these results indicate that the cholinergic neurons were highly expressed in the hippocampal CA1 PV GABAergic neurons.

\section{Decreased Activity of $\alpha 7$ nAChRs Could Increase the Seizure Susceptibility in C57BI/6 Wild-Type Mice}

To investigate the effects of $\alpha 7 \mathrm{nAChRs}$ on seizure susceptibility in C57BL/6 wild-type mice, we injected PNU282987
(1 M) and MLA (100 nM) into the hippocampus in the CA1 by microtubule drug administration. Scopolamine methylnitrate (1 $\mathrm{mg} / \mathrm{kg} \quad$ s.c.; Sigma) was administered $30 \mathrm{~min}$ before pilocarpine injection to avoid peripheral cholinergic effects (18). We measured seizure susceptibility by injecting the cholinergic agonist pilocarpine $(250 \mathrm{mg} / \mathrm{kg}$ i.p.) following intraperitoneal administration, which acts on muscarinic receptors.

To observe the electrographic changes caused by pilocarpineinduced seizures between the vehicle and $\alpha 7 \mathrm{nAChR}$ agonist and antagonist, we recorded EEGs using bilateral epidural screw electrodes (see Methods section) and quantified the electrographic seizures by the latency of onset time, the latency of GTC, and the latency of death. After $10 \mathrm{~min}$ baseline recording, we administrated the vehicle and PNU282987 in the CA1 of the hippocampus in C57BL/6 wildtype mice. After recording the EEGs for $15 \mathrm{~min}$, we injected pilocarpine following intraperitoneal administration to induce epilepsy. The results showed that there was no significant difference in the onset time of epilepsy and the latency of GTC (Figures 2A-C). Moreover, we found the latency of death was slightly prolonged after administration of PNU282987, but there was no significant difference between the vehicle-treated control group and the C57BL/6 wild-type group (Figure 2D). However, the latency of onset time, the latency of GTC, and the latency of death were significantly shortened with MLA treatment (Figures 2A-D). The results indicated that a decrease in the activity of $\alpha 7 \mathrm{nAChRs}$ could increase seizure susceptibility but the increased activity of $\alpha 7$ nAChRs has no effect.

\section{Decreased Activity of $\alpha 7$ nAChRs Could Increase the Excitability of the CA1 Pyramidal Neurons in the Hippocampus in C57BL/6 Wild-Type Mice}

To further demonstrate the effect of $\alpha 7 \mathrm{nAChRs}$, we recorded the excitability of CA1 pyramidal neurons by checking the number of action potentials (APs) elicited by current injections of various amplitudes ( $1 \mathrm{~s}, 0$ to $+250 \mathrm{pA})$ in the acute cortical slices. All pyramidal neurons showed high-frequency discharges with increasing currents. We assessed the effect of PNU282987 $(1 \mu \mathrm{m})$, a selective $\alpha 7 \mathrm{nAChR}$ agonist, on hippocampal slices from C57BL/6 mice. In contrast to the control group, there was no significant change in the excitability of pyramidal neurons in C57BL/6 wide-type mice (Figures 3A,B). However, with the bath application of MLA (10 nM), a specific $\alpha 7 \mathrm{nAChR}$ blocker, the number of APs was significantly higher in the C57BL/6 group compared with that in the control group (Figures 3C,D). Taken together, these results revealed that a decrease in the activity of $\alpha 7 \mathrm{nAChRs}$ could increase the excitability of CA1 pyramidal neurons in the hippocampus.

We believed that the effect of $\alpha 7 \mathrm{nAChRs}$ on pyramidal neuron excitability could be due to the following two possibilities: the inhibitory input from parvalbumin (PV) interneurons to pyramidal neurons, and the direct modulation of $\alpha 7 \mathrm{nAChRs}$ on pyramidal neurons (19). To distinguish between the two possibilities, we administered DL-APV, DNQX, and picrotoxin 


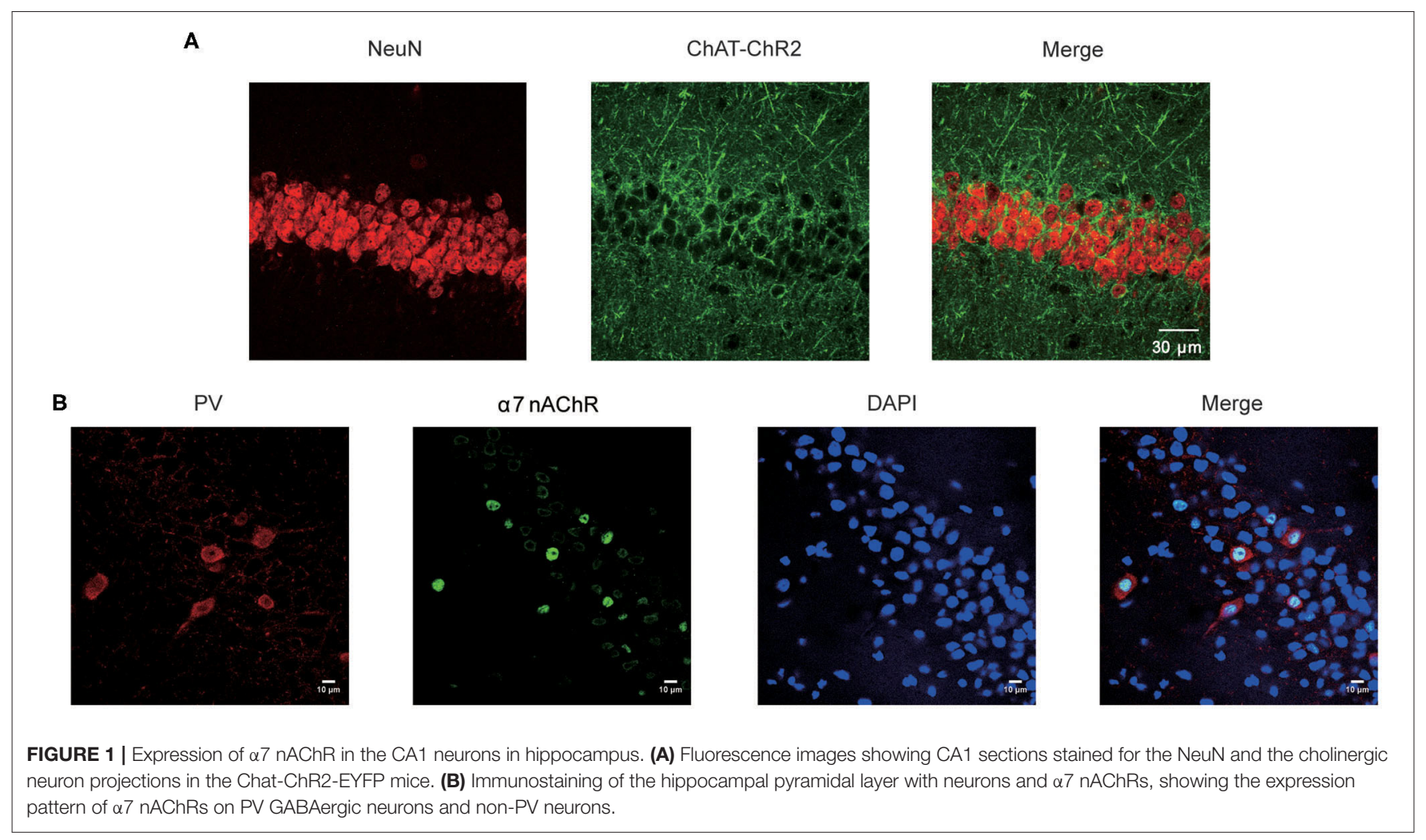

to block NMDA-mediated, AMPA-mediated, and GABAAmediated synaptic transmission, respectively. The results showed that there was a slight increase but no significant change of pyramidal neuron excitability after the application of MLA $(10 \mathrm{nM})$, suggesting that the excitability of pyramidal neurons is mostly regulated by the inhibitory input from PV neurons (Figures 3E,F).

To further study the effect of MLA on the excitability of CA1 pyramidal neurons in epileptic brain slices. We recorded the excitability of CA1 pyramidal neurons in epileptic brain slices before and after administrating MLA. The excitability of pyramidal neurons was increased after epilepsy, and the excitability is slightly higher after adding MLA. However, there was no significant difference in pyramidal neuron excitability after the application of MLA (Figures 3G,H). The results indicate that the $\alpha 7 \mathrm{nAChRs}$ on pyramidal neurons may also play a role in regulating excitability.

\section{Decreased $\alpha 7$ nAChR Expression in Human Epileptogenic Tissues}

To further confirm the association between the activity of $\alpha 7$ nAChRs and seizure susceptibility, we assessed the expression of $\alpha 7 \mathrm{nAChRs}$ in cell membranes by immunoblotting from the epileptogenic foci tissue between subjects with secondary and intractable epilepsy and the those with traumatic brain injury (Figure 4A). The results showed that the level of $\alpha 7 \mathrm{nAChRs}$ in the epilepsy samples was only $\sim 50 \%$ of that in the control group
(Figure 4B). This observation is also supported by a decrease in $\alpha 7 \mathrm{nAChR}$ expression in human epileptogenic tissues.

\section{DISCUSSION}

This study investigated the association between the activity of $\alpha 7$ nAChRs and seizure susceptibility. We presented evidence that decreased activity of $\alpha 7 \mathrm{nAChRs}$ could increase seizure susceptibility in C57BL/6 wild-type mice. First, we proved that cholinergic neurons exist, and its subunit receptor- $\alpha 7$ nAChRs mostly expressed in CA1 PV interneurons. Second, we studied seizure susceptibility after the stimulation and inhibition of $\alpha 7$ nAChRs. To address this issue, we used C57BL/6 wild-type mice experiencing pilocarpine-induced seizures as the experimental animals. The results showed that the seizure susceptibility between the PNU282987-treated mice and the control group was not significantly different, but the MLA-treated mice could significantly shorten the seizure susceptibility. Third, the number of APs was significantly increased after MLA treatment; however, there were no significant differences after infusion of PNU282987 in CA1 pyramidal neurons. Furthermore, we found that the excitability of pyramidal neurons was mostly regulated by $\alpha 7$ nAChRs receptors of PV GABAergic neurons. Finally, the study showed that the expression of $\alpha 7 \mathrm{nAChR}$ protein was reduced in the epileptogenic foci tissue from individuals. In summary, our study identified that decreased $\alpha 7 \mathrm{nAChRs}$ may be a risk factor for seizure susceptibility. 


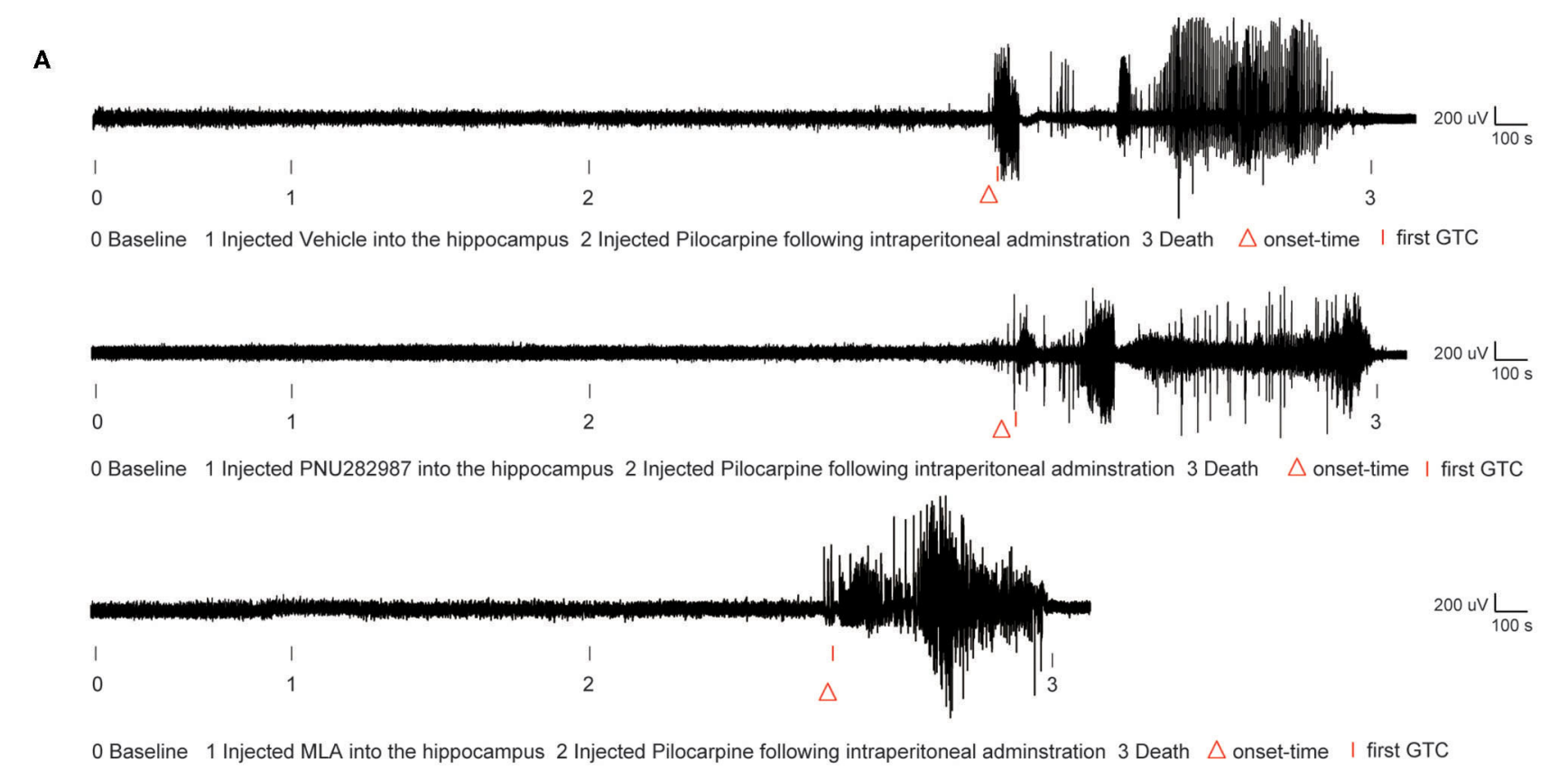

B

C
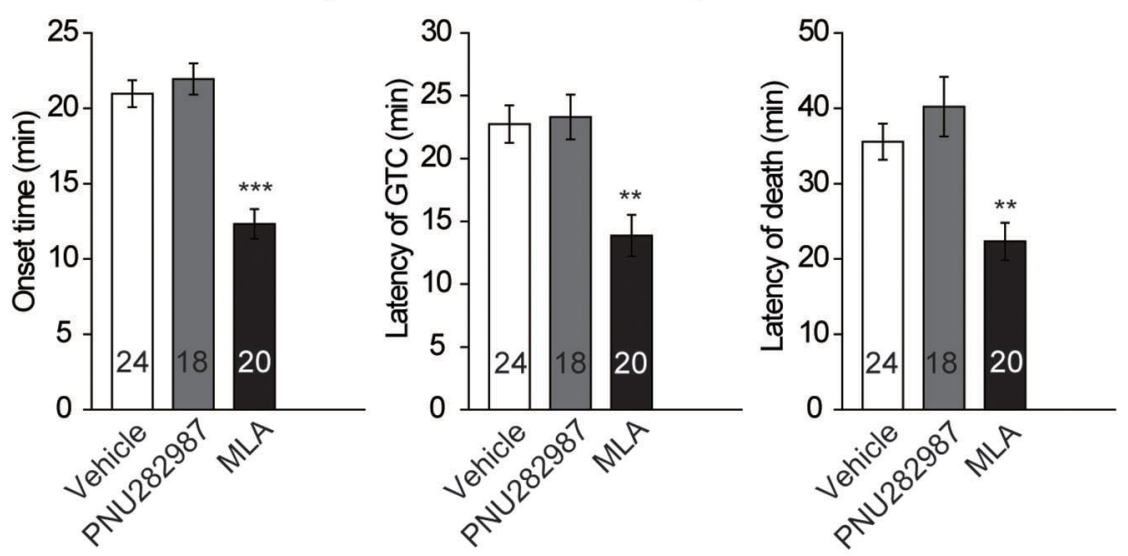

FIGURE 2 | Decreased activity of $\alpha 7$ nAChRs could increase the seizure susceptibility in C57BL/6 wild-type mice. (A) Representative compressed electroencephalogram from a cortical lead depicting an electrographic seizure in a C57BL/6 mouse with seizure behaviors identified at the time of occurrence. Background EEG baseline is shown before seizure onset. (B-D) Summary histograms of the onset time, latency of GTC, and latency of death, respectively. Two-way ANOVA was used. ${ }^{\star \star \star} P<0.001 ;{ }^{\star \star} P<0.01$; vs. to vehicle. Error bars are means \pm s.e.m.

It has been reported that $\alpha 7 \mathrm{nAChRs}$ are widely expressed in the hippocampus and thalamus, but they are observed at low levels in the postmortem human brain $(20,21)$. The $\alpha 7 \mathrm{nAChRs}$ are concentrated on almost all synapses both presynaptically and postsynaptically in the CA1 region of the hippocampus (22). The initial evidence of $\alpha 7 \mathrm{nAChR}$ activity in synapses was obtained from rat hippocampal CA1 pyramidal neurons by examining rats' spontaneous activity (23-25). Loss of $\alpha 7$ nAChRs may play a pivotal role in cognitive function damage (26-29). Previous studies have shown that $\alpha 7 \mathrm{nAChRs}$ have neuroprotective effects (30). The administration of nicotine may attenuate microglial activity and increase the eclampsialike seizure threshold in the rat hippocampus through the $\alpha 7$ nicotinic receptor (31). This revealed the influence of $\alpha 7$ nAChRs on the threshold in pregnant rats. Previous studies have shown that activation of $\alpha 7 \mathrm{nAChRs}$ could decrease the seizure susceptibility in Chat-Mecp $2^{-/ y}$ mice (16). Therefore, we hypothesized that $\alpha 7 \mathrm{nAChRs}$ may be associate with epilepsy. In this present study, immunofluorescence results on hippocampal neurons showed that $\alpha 7 \mathrm{nAChRs}$ are expressed in pyramidal and 


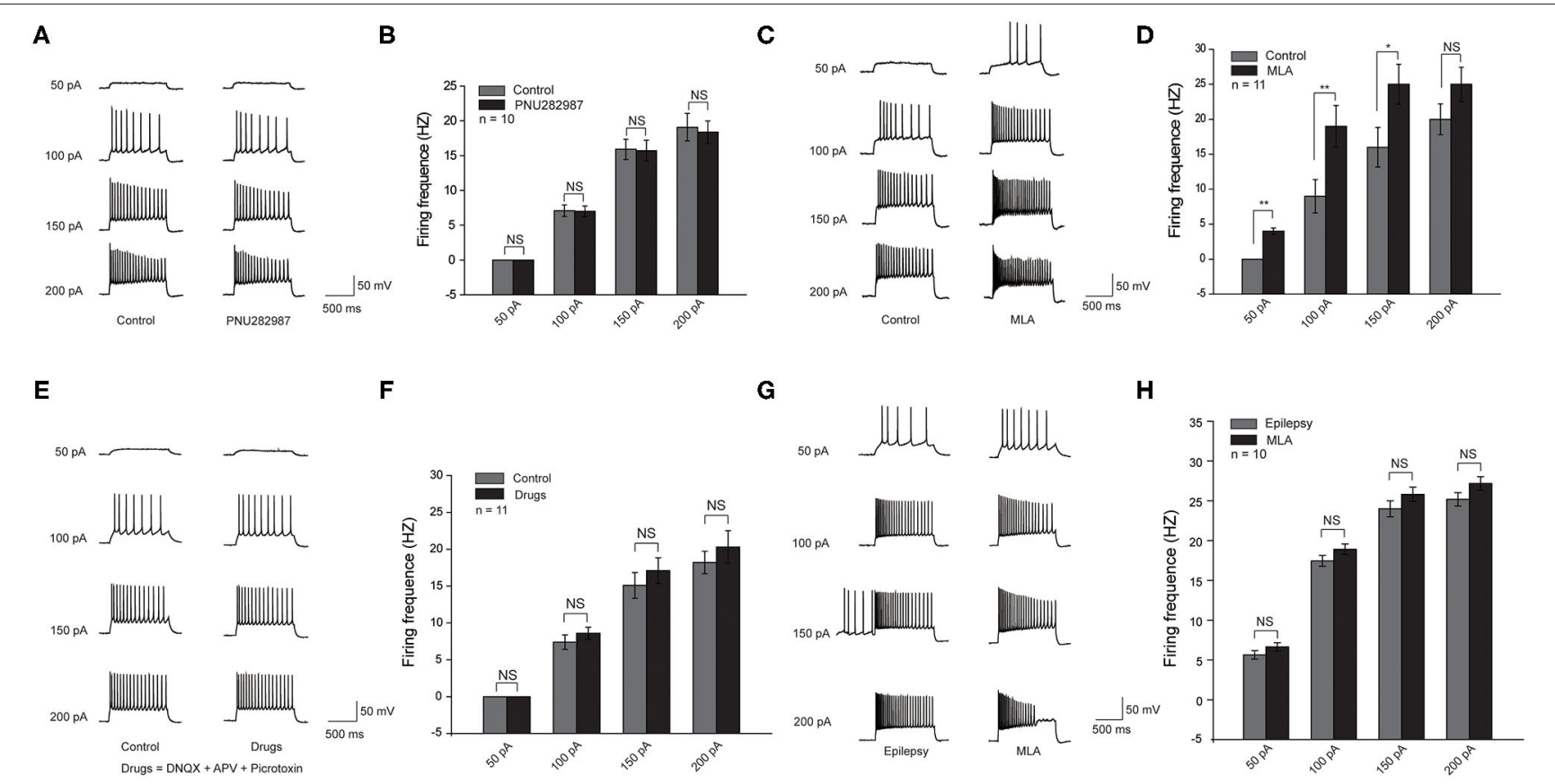

FIGURE 3 | Decreased activity of $\alpha 7$ nAChRs could increase the excitability of the CA1 pyramidal neurons in the hippocampus in C57BL/6 wild-type mice. (A,C,E,G) Voltage responses of a representative to in pyramidal neurons to various injection steps (1s) from top to bottom, 50, 100, 150, 200 pA. (A) Left: Control group. Right: PNU282987 group. (B) Summary histogram showing the number of pyramidal neuron APs. Two-way ANOVA was used. $n=10$. (C) Left: Control group. Right: MLA group. (D) Summary histogram showing the number of pyramidal neuron APs. Two-way ANOVA was used. $n=11$. (E) Left: Control group. Right: Drugs group (Drugs $=$ DNQX + APV + Picrotoxin). (F) Summary histogram showing the number of pyramidal neuron APs. Two-way ANOVA was used. $n=11$. (G) Left: Epilepsy group. Right: MLA group. (H) Summary histogram showing the number of pyramidal neuron APs. All pyramidal neuron membrane potential was kept at -70 mV by injecting a small DC current through the recording pipette. $P$-value was calculated by two-sided $t$-test. ${ }^{\star \star} P<0.01 ;{ }^{\star} P<0.05$. Error bars are means \pm s.e.m.

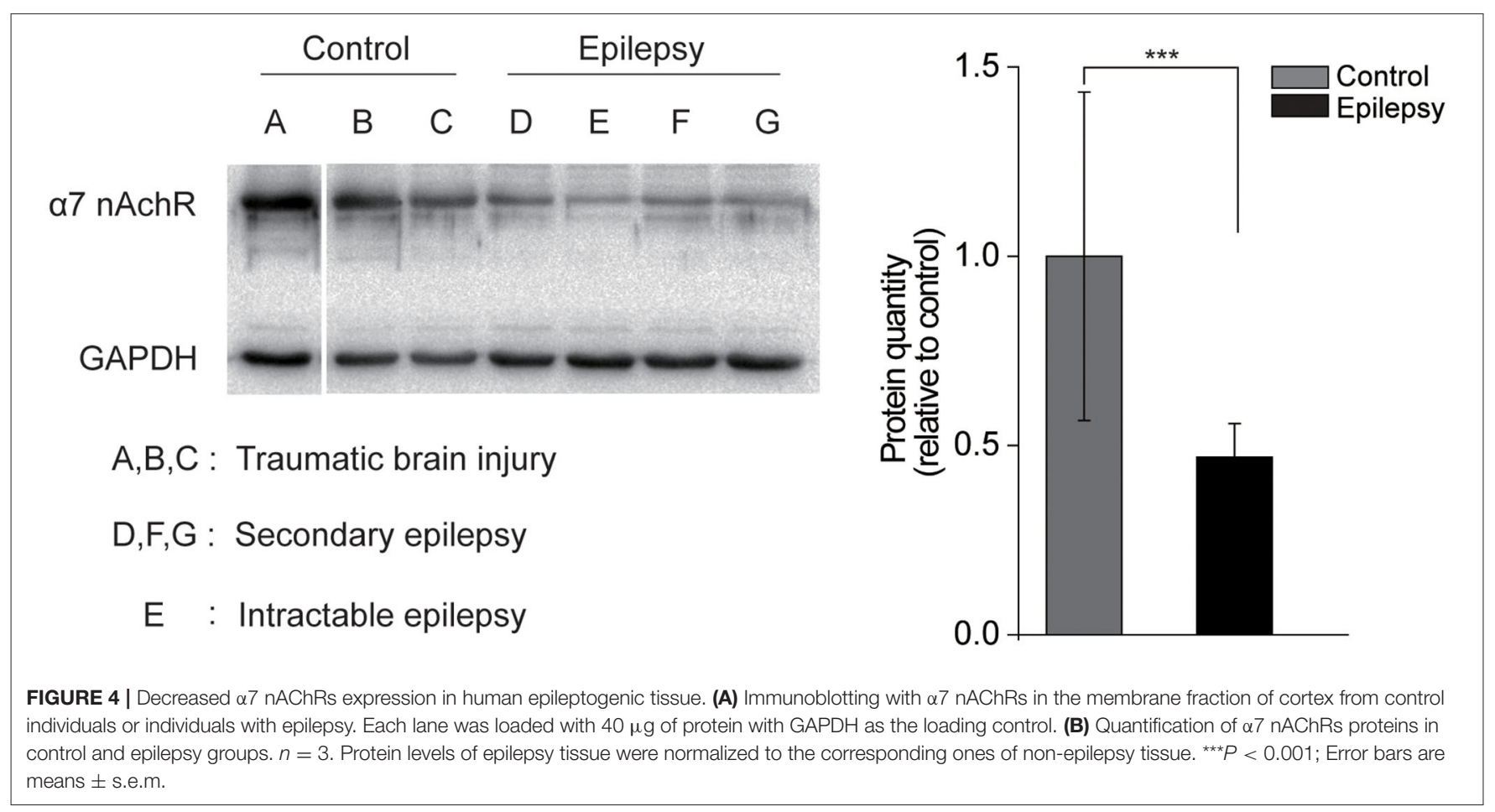


PV neurons in the hippocampus. Previous studies showed that PV interneuron axons project to the peribody area of pyramidal neurons and regulate the activity of pyramidal neurons (32). We revealed that treatment with MLA to block $\alpha 7$ nAChRs on CA1 PV interneurons indirectly increased the excitability of these neurons. Further studies are required to examine whether $\alpha 7$ nAChRs in pyramidal neurons affect its excitability. This study only tested the role of $\alpha 7 \mathrm{nAChRs}$ in the pilocarpine model, and further studies are required to confirm its effects in more epilepsy models.

Decreased excitability of $\alpha 7$ nAChRs on CA1 pyramidal neurons in the hippocampus leads to high seizure sensitivity in mice. $\alpha 7 \mathrm{nAChR}$ antagonists have been reported to alter the frequency and amplitude of glutamatergic neurons recorded from pyramidal neurons in hippocampal samples obtained from patients with mesial temporal lobe epilepsy with hippocampal sclerosis (33). The results of this study also suggested that the application of $\alpha 7$ receptor antagonists in patients with temporal lobe epilepsy could overexcite pyramidal neurons, a result similar to that of our study. A recent study also demonstrated that the $\alpha 7 \mathrm{nAChR}$ agonist choline chloride could improve epilepsy, depression, and memory deficits in the PTZ-kindled mouse model (34). This also suggests that $\alpha 7 \mathrm{nAChRs}$ play a pivotal role in epilepsy. Moreover, in our study, the expression of $\alpha 7 \mathrm{nAChRs}$ was reduced in human epileptogenic tissues. Our findings suggest that the downregulation of $\alpha 7 \mathrm{nAChRs}$ contributes to human epilepsy. However, the increased activity of $\alpha 7 \mathrm{nAChRs}$ on CA1 pyramidal neurons in the hippocampus had no significant effect on seizure sensitivity. Earlier studies also showed that selective allosteric modulators of $\alpha 7 \mathrm{nAChRs}$ could have potential therapeutic applications in epilepsy (35). Overall, our results suggest that $\alpha 7 \mathrm{nAChRs}$ are an essential regulator of seizure susceptibility.

\section{REFERENCES}

1. Hasselmo ME, Sarter M. Modes and models of forebrain cholinergic neuromodulation of cognition. Neuropsychopharmacology. (2011) 36:52-73. doi: 10.1038/npp.2010.104

2. Lindstrom JM. Hand Book of Receptors and Channels: Ligand-and VoltageGated Ion Channels. In: North A, editor. Boca Raton, FL: CRC Press (1995). p. 153-75.

3. Leonard S, Bertrand D. Neuronal nicotinic receptors: from structure to function. Nicotine Tob Res. (2001) 3:203-23. doi: 10.1080/14622200110050213

4. Novere NL, Changeux JP. Molecular evolution of the nicotinic acetylcholine receptor: an example of multigene family in excitable cells. J Mol Evol. (1995) 40:155-72. doi: 10.1007/BF00167110

5. Corringer PJ, Novere NL, Changeux JP. Nicotinic receptors at the amino acid level. Annu Rev Pharmacol Toxicol. (2000) 40:431-58. doi: 10.1146/annurev.pharmtox.40.1.431

6. Albuquerque EX, Alkondon M, Pereira EF, Castro NG, Schrattenholz A, Barbosa CT, et al. Properties of neuronal nicotinic acetylcholine receptors: pharmacological characterization and modulation of synaptic function. $J$ Pharmacol Exp Ther. (1997) 280: 1117-1136.

7. Kihara T, Shimohama S, Sawada H, Honda K, Nakamizo T, Shibasaki H, et al. $\alpha 7$ nicotinic receptor transduces signals to phosphatidylinositol 3-kinase to block A $\beta$-amyloid-induced neurotoxicity. J Biol Chem. (2001) 276:13541-6. doi: 10.1074/jbc.M008035200

\section{DATA AVAILABILITY STATEMENT}

The datasets generated for this article are not readily available because this would jeopardize patient privacy. Requests to access the datasets should be directed to sp120@zju.edu.cn.

\section{ETHICS STATEMENT}

The studies involving human participants were reviewed and approved by Medical Ethical Committee of Zhejiang Provincial People's Hospital, People's Hospital of Hangzhou Medical College. The patients/participants provided their written informed consent to participate in this study. The animal study was reviewed and approved by Medical Ethical Committee of Zhejiang Provincial People's Hospital, People's Hospital of Hangzhou Medical College. Written informed consent was obtained from the owners for the participation of their animals in this study.

\section{AUTHOR CONTRIBUTIONS}

PS conducted the immunohistochemistry, western blot analysis, electrophysiology experiments, analyzed data, and wrote the manuscript. D-GL conducted the animal behavioral studies, EEG recordings, and collected the data. X-MY supervised all phases of the project and approved the final manuscript. All authors contributed to the article and approved the submitted version.

\section{FUNDING}

This work was supported by the Medical Science and Technology Project of Zhejiang Provincial (2020KY435).

8. Zoli M, Picciotto MR, Ferrari R, Cocchi D, Changeux JP. Increased neurodegeneration during ageing in mice lacking high-affinity nicotine receptors. EMBO J. (1999) 18:1235-44. doi: 10.1093/emboj/18.5.1235

9. Gu W, Bertrand D, Steinlein OK. A major role of the nicotinic acetylcholine receptor gene CHRNA2 in autosomal dominant nocturnal frontal lobe epilepsy (ADNFLE) is unlikely. Neurosci Lett. (2007) 422:74-6. doi: 10.1016/j.neulet.2007.06.006

10. Becchetti A, Aracri P, Meneghini S, Brusco S, Amadeo A. The role of nicotinic acetylcholine receptors in autosomal dominant nocturnal frontal lobe epilepsy. Front Physiol. (2015) 6:22. doi: 10.3389/fphys.2015.00022

11. Séguéla P, Wadiche J, Dineley-Miller K, Dani JA, Patrick JW. Molecular cloning, functional properties, and distribution of rat brain $\alpha 7$ : a nicotinic cation channel highly permeable to calcium. J Neurosci. (1993) 13:596-604. doi: 10.1523/JNEUROSCI.13-02-00596.1993

12. Soler-Alfonso C, Carvalho CM, Ge, J, Roney EK, Bader PI, Kolodziejska $\mathrm{KE}$, et al. CHRNA7 triplication associated with cognitive impairment and neuropsychiatric phenotypes in a three-generation pedigree. Eur J Hum Genet. (2014) 22:1071-6. doi: 10.1038/ejhg.2013.302

13. Musso F, Bettermann F, Vucurevic G, Stoeter P, Konrad A, Winterer G. Smoking impacts on prefrontal attentional network function in young adult brains. Psychopharmacology. (2007) 191:159-69. doi: 10.1007/s00213-006-0499-8

14. Parikh V, Ji J, Decker MW, Sarter, M. Prefrontal beta2 subunitcontaining and alpha7 nicotinic acetylcholine receptors differentially control 
glutamatergic and cholinergic signaling. J Neurosci. (2010) 30:3518-30. doi: 10.1523/JNEUROSCI.5712-09.2010

15. Wallace TL, Bertrand D. Importance of the nicotinic acetylcholine receptor system in the prefrontal cortex. Biochem Pharmacol. (2013) 85:1713-20. doi: 10.1016/j.bcp.2013.04.001

16. Zhang Y, Cao SX, Sun P, He HY, Yang CH, Chen XJ, et al. Loss of MeCP2 in cholinergic neurons causes part of RTTlike phenotypes via $\alpha 7$ receptor in hippocampus. Cell Res. (2016) 26:1-15. doi: 10.1038/cr.2016.48

17. Picciotto MR, Higley MJ, Mineur YS. Acetylcholine as a neuromodulator: Cholinergic signaling shapes nervous system function and behavior. Neuron. (2012) 76:116-29. doi: 10.1016/j.neuron.2012.08.036

18. Turski L, Cavalheiro EA, Sieklucka-Dziuba M, Ikonomidou-Turski C, Czuczwar SJ, Turski WA. Seizures produced by pilocarpine: neuropathological sequelae and activity of glutamate decarboxylase in the rat forebrain. Brain Res. (1986) 398:37-48. doi: 10.1016/0006-8993(86) 91247-3

19. Xu M, Sun P, Zhang Y, Yang CH, Wei X, Ma XX, et al. DV21 decreases excitability of cortical pyramidal neurons and acts in epilepsy. Sci Rep. (2017) 7:1701. doi: 10.1038/s41598-017-01734-z

20. Bertrand D, Lee CHL, Flood D, Marger F, Roberts D.D. Therapeutic potential of a7 nicotinic acetylcholine receptors. Pharmacol Rev. (2015) 67:1025-73. doi: 10.1124/pr.113.008581

21. Breese CR, Adams C, Logel J, Drebing C, Rollins Y, Barnhart M, et al. Comparison of the regional expression of nicotinic acetylcholine receptor alpha7 mRNA and 125I-alphabungarotoxin binding in human postmortem brain. J Comp Neurol. (1997) 387:385-98

22. Kawai H, Zago W, Berg DK. Nicotinic alpha 7 receptor clusters on hippocampal GABAergic neurons: regulation by synaptic activity and neurotrophins. $J$ Neurosci. (2002) 22:7903-12. doi: 10.1523/JNEUROSCI.22-18-07903.2002

23. Alkondon M, Pereira EF, Albuquerque EX. alpha-bungarotoxin- and methyllycaconitine-sensitive nicotinic receptors mediate fast synaptic transmission in interneurons of rat hippocampal slices. Brain Res. (1998) 810:257-63. doi: 10.1016/S0006-8993(98)00880-4

24. Frazier CJ, Buhler AV, Weiner JL, Dunwiddie TV. Synaptic potentials mediated via alpha-bungarotoxin-sensitive nicotinic acetylcholine receptors in rat hippocampal interneurons. J Neurosci. (1998) 18:8228-35. doi: 10.1523/JNEUROSCI.18-20-08228.1998

25. Hefft S, Hulo S, Bertrand D, Muller D. Synaptic transmission at nicotinic acetylcholine receptors in rat hippocampal organotypic cultures and slices. $J$ Physiol. (1999) 515:769-76. doi: 10.1111/j.1469-7793.1999.769ab.x

26. Nordberg A. Neuroprotection in Alzheimer's disease - new strategies for treatment. Neurotox Res. (2000) 2:157-65. doi: 10.1007/BF03033791

27. Nordberg A, Lundqvist H, Hartvig P, Andersson J, Johansson M, HellstromLindahi E, et al. Imaging of nicotinic and muscarinic receptors in Alzheimer's disease: effect of tacrine treatment. Dement Geriatr Cogn Disord. (1997) 8:78-84. doi: $10.1159 / 000106611$

28. Whitehouse PJ, Kalaria RN. Nicotinic receptors and neurodegenerative dementing diseases: basic research and clinical implications. Alzheimer Dis Assoc Disord. (1995) 9:S3-5. doi: 10.1097/00002093-199501002-00002

29. Guan ZZ, Zhang X, Ravid R, Nordberg A. Decreased protein levels of nicotinic receptor subunits in the hippocampus and temporal cortex of patients with Alzheimer's disease. J Neurochem. (2000) 74:237-43. doi: 10.1046/j.1471-4159.2000.0740237.x

30. Li XD, Buccafusco JJ. Effect of $\beta$-amyloid peptide 1-42 on the cytoprotective action mediated by $\alpha 7$ nicotinic acetylcholine receptors in growth factordeprived differentiated PC-12 cells. J Pharmacol Exp Ther. (2003) 307:670-5. doi: 10.1124/jpet.103.053785

31. Li XL, Han XJ, Bao JJ, Liu YY, Ye AH, Thakur M, et al. Nicotine increases eclampsia-like seizure threshold and attenuates microglial activity in rat hippocampus through the $\alpha 7$ nicotinic acetylcholine receptor. Brain Res. (2016) 1642:487-96. doi: 10.1016/j.brainres.2016.04.043

32. Goldberg EM, Clark BD, Zagha E, Nahmani M, Erisir A, Rudy B. K+ channels at the axon initial segment dampen near-threshold excitability of neocortical fast-spiking GABAergic interneurons. Neuron. (2008) 58:387-400. doi: 10.1016/j.neuron.2008.03.003

33. Banerjee J, Dey S, Dixit AB, Tripathi M, Doddamani R, Sharma MC, et al. $\alpha 7$ nicotinic receptors contributes to glutamatergic activity in the hippocampus of patients with mesial temporal lobe epilepsy with hippocampal sclerosis (MTLE-HS). J Neural Transm (Vienna). (2020) 127:1441-6. doi: 10.1007/s00702-020-02239-2

34. Sharma NK, Kaur S, Goel RK. Exploring the ameliorative role of $\alpha 7$ neuronal nicotinic acetylcholine receptor modulation in epilepsy and associated comorbidities in post PTZ-kindled mice. Epilepsy Behav. (2019) 103:106862. doi: 10.1016/j.yebeh.2019.106862

35. Arnaiz-Cot JJ, González JC, Sobrado M, Baldelli P, Carbone E, Gandía L, et al Allosteric modulation of alpha 7 nicotinic receptors selectively depolarizes hippocampal interneurons, enhancing spontaneous GABAergic transmission. Eur J Neurosci. (2008) 27:1097-110. doi: 10.1111/j.1460-9568.2008.06077.x

Conflict of Interest: The authors declare that the research was conducted in the absence of any commercial or financial relationships that could be construed as a potential conflict of interest.

Copyright (c) 2021 Sun, Liu and Ye. This is an open-access article distributed under the terms of the Creative Commons Attribution License (CC BY). The use, distribution or reproduction in other forums is permitted, provided the original author(s) and the copyright owner(s) are credited and that the original publication in this journal is cited, in accordance with accepted academic practice. No use, distribution or reproduction is permitted which does not comply with these terms. 